\title{
Trabalho docente, desigualdades de gênero e saúde em universidade pública
}

\author{
The work of professors, gender inequalities, and health \\ at public universities
}

Katia Reis de Souza (http://orcid.org/0000-0002-2084-2606) ${ }^{1}$

Regina Helena Simões-Barbosa (http://orcid.org/0000-0002-1161-7220) ${ }^{2}$

Andréa Maria dos Santos Rodrigues (http://orcid.org/0000-0001-8254-341X) ${ }^{1}$

Eliana Guimarães Felix (http://orcid.org/0000-0002-3548-1356) ${ }^{1}$

Luciana Gomes (https://orcid.org/0000-0003-2038-0859) ${ }^{1}$

Maria Blandina Marques dos Santos (http://orcid.org/0000-0002-0065-5635) ${ }^{1}$
${ }^{1}$ Centro de Estudos da Saúde do Trabalhador e Ecologia Humana, Escola Nacional de Saúde Pública Sergio Arouca, Fundação Oswaldo Cruz. R. Leopoldo Bulhões 1480, Manguinhos. 21041-210 Rio de Janeiro RJ Brasil. katreis@ensp. fiocruz.br

${ }^{2}$ Instituto de Estudos em Saúde Coletiva, Universidade Federal do Rio de Janeiro. Rio de Janeiro RJ Brasil.

\begin{abstract}
This study aimed to problematize aspects of the work of professors in relation to gender, assessment policies, and health. For this purpose, a qualitative social investigation was conducted within the aspect of participatory studies and the views of materialist feminism. An analysis of the material was carried out through content analysis, according to the topic, using four main themes: conflicts between professors' work and domestic work; professors' work, motherhood, and guilt; policies for the assessment of professors and gender relations; and the sexual division of labor and teaching. It was possible to perceive just how much the demands of the productive sphere have gone beyond the time of the workday and into the reproductive sphere and the private life of professors, compromising the struggle for health and leading to processes of suffering and illness. The theme of the sexual division of labor in public universities appears to be an important issue that highlights work overload and psychological illness, especially at a time when the teaching profession is becoming increasingly competitive. In conclusion, we believe that there is an imperative need for investments in public policies that can guarantee gender equality in higher education.
\end{abstract}

Key words The work of professors, Gender, Workers' health, Public university
Resumo Oobjetivo do presente estudo foi problematizar aspectos do trabalho docente do ensino superior em relação a gênero, políticas de avaliação e saúde. Para tal, realizou-se uma pesquisa social de caráter qualitativo sob a vertente dos estudos participativos e do enfoque do feminismo materialista. A análise do material foi efetuada por meio da análise de conteúdo, na modalidade temática, e identificados quatro temas principais: conflitos entre trabalho docente e trabalho doméstico; trabalho docente, maternidade e culpa; politicas de avaliação do trabalho docente e relações de gênero; divisão sexual do trabalho e docência. Percebeuse o quanto as demandas da esfera produtiva têm extrapolado o tempo da jornada de trabalho para a esfera reprodutiva e a vida privada das professoras, comprometendo a luta e a defesa pela saúde que podem levar a processos de sofrimento e adoecimento. O tema da divisão sexual do trabalho em universidades públicas desponta como importante questão que evidencia sobrecarga de trabalho e mal estar psíquico, especialmente em um momento em que o trabalho docente se torna crescentemente competitivo. Concluiu-se pela imperativa necessidade de investimentos em políticas públicas que garantam igualdade de gênero no trabalho do ensino superior.

Palavras-chave Trabalho docente, Gênero, Saúde do trabalhador, Universidade pública 


\section{Introdução}

No Brasil, desde a década de 1990, a universidade pública vem sendo submetida à racionalidade de mercado e aos imperativos da reestruturação produtiva de caráter neoliberal. Sob a égide do capitalismo ultraneoliberal, a pesquisa, a ciência e a tecnologia são vistas como áreas potenciais para se gerar lucro, sendo a educação, ela própria, considerada como mercadoria. No tocante às políticas públicas de ensino superior implantadas nas últimas décadas, sobretudo no atual governo, exacerba-se a ideia segundo a qual as universidades são vistas como espaços estratégicos para o desenvolvimento do empreendedorismo $^{1}$. Como desdobramento, tomam corpo no trabalho docente aspectos como competição, individualismo e produtivismo, entre outras características típicas do capitalismo organizacional e gerencialista ${ }^{2,3}$. E, de fato, em suas novas configurações, o trabalho docente vem tornando-se crescentemente competitivo e baseado em critérios rigorosos de produtividade, especialmente no âmbito da pós-graduação, acarretando conflitos que levam a processos de adoecimento físico e psíquico ${ }^{4}$, mas com poucos estudos que adotam o enfoque das relações sociais de sexo ${ }^{5}$.

Neste estudo, defende-se a tese segundo a qual promover a equidade entre homens e mulheres na carreira acadêmica é matéria fundamental à saúde dos trabalhadore(a)s de universidades públicas sob a perspectiva das relações de gênero. De acordo com Schneider ${ }^{6}$, é preciso elucidar violências que perpetuam a divisão sexual do trabalho e a submissão das mulheres na organização universitária, desde suas tarefas cotidianas até suas agendas de pesquisa e extensão.

Ademais, deve-se destacar o ponto alusivo à desigualdade de gênero nas relações de trabalho, pois mulheres têm enfrentado jornadas opressivas, tanto na esfera produtiva como na reprodutiva. Para Siqueira ${ }^{7}$, à acentuada intensificação laboral e precarização das condições de trabalho em universidades públicas, se somam o adoecimento, assédio moral e sexual e enfrentamento do machismo na esfera política e sindical. O estudo de Araújo et al. ${ }^{8}$ chama atenção para o fato de que homens têm sido considerados o padrão -ouro com o qual as mulheres vêm sendo comparadas em diferentes esferas da educação, persistindo diferenças de atribuições e de valorização social do trabalho segundo o gênero. $\mathrm{O}$ mencionado estudo foi realizado na educação básica de escolas públicas e mostrou que professoras apresentaram maior carga horária semanal de traba- lho, maior proporção de sobrecarga doméstica e menor nível de participação política no processo decisório do trabalho do que os homens.

Consoante Velho e León ${ }^{9}$, várias têm sido as tentativas de explicar porque as mulheres, mesmo depois de conseguirem vencer as barreiras de acesso à carreira acadêmica, não avançam na mesma proporção e velocidade que os homens. A explicação tradicional adota uma visão simplista e preconceituosa de que mulheres produzem, cientificamente, menos que os homens. Esta menor produtividade das mulheres, no entanto, tem sido bastante relativizada em estudos que procuram entender os contextos, motivações e condições de produção de homens e mulheres na academia. Esses mesmos autores já apontavam, no final da década de 1990, para a importância de se considerar fatores tais como conflitos família-trabalho, níveis de investimento na educação feminina, além de mecanismos sutis de discriminação.

No que tange especificamente à saúde docente, o estudo de Hoffmann et al..$^{10}$ relacionou, fortemente, o esgotamento profissional docente com a organização do trabalho acadêmico. No caso das docentes, esse quadro de esgotamento profissional parece estar, também, associado à falta de reconhecimento entre pares. Observouse que as mulheres são mais impactadas pelos sentimentos de desvalorização, injustiça e desqualificação. Descartou-se a ideia de que homens e mulheres submetidos ao mesmo contexto de trabalho, no que se refere ao ambiente do magistério superior, apresentem, em mesma proporção, vivências de prazer e sofrimento, e, por isso, estejam expostos ao mesmo grau de riscos de adoecimento. A situação desfavorável percebida pelas mulheres refere-se, entre outros aspectos, à sobrecarga da "conciliação" entre vida doméstica e profissional. De acordo com os autores, o papel de gênero deve ser considerado enquanto elemento que promove distinção no trabalho e vulnerabilidade aos riscos de adoecimento. Nesse sentido, é digna de nota a observação de Hirata e Kergoat ${ }^{11}$, ao sugerirem a substituição da ideia de "conciliação" por "conflito", "tensão", "contradição", para evidenciar a natureza fundamentalmente conflituosa da incumbência simultânea de responsabilidades profissionais e familiares às mulheres. De acordo com as autoras, o pensamento crítico da "conciliação" não pode se desenvolver fora do contexto de reflexão sobre as modalidades de reprodução da servidão doméstica. Assim, consideram relevantes aspectos psicológicos tais como afetividade e formas de dominação 
que perpetuam a divisão sexual do trabalho na esfera produtiva e reprodutiva.

Nesse escopo de compreensão, entende-se que, em um trabalho de natureza intelectual, como o de professor(a) universitário(a), que exige um alto grau de qualificação profissional para o ingresso na carreira, torna-se pertinente conhecer como professoras percebem as repercussões da divisão sexual de trabalho e como vêm lidando com o difícil e conflitivo manejo do cotidiano na atividade acadêmica. Assim, tem-se como principal objetivo desse estudo problematizar aspectos do trabalho docente do ensino superior no que diz respeito às relações de gênero, às políticas de avaliação e à saúde com foco no diálogo com docentes de universidade pública.

\section{Referencial teórico}

Dentro do escopo de vertentes teórico-políticas do feminismo, nos alinhamos à corrente materialista dialética, segundo a qual o trabalho é central em sua materialidade histórico-social e enquanto prática política de resistência. Neste enfoque, se reconhece ainda a importância capital do trabalho como motor da emancipação humana, individual e coletiva ${ }^{12}$. Esta perspectiva propugna, ainda, três tipos de indissociabilidades, a saber: entre vida material e simbólica, não desvinculando as determinações econômicas das esferas culturais e simbólicas; entre as esferas da produção e da reprodução social, visibilizando o valor do trabalho doméstico; e, por fim, entre as dimensões de gênero, classe e raça, que se entrelaçam, sob o capitalismo, para otimizar a extração de mais valia ${ }^{13-16}$

É por meio deste feminismo materialista dialético e, por definição, anti-capitalista ${ }^{17}$, que analisaremos as relações entre gênero, trabalho docente universitário e saúde. Para empreendermos essa análise, o conceito de divisão sexual do trabalho é fundamental para compreensão crítica do trabalho feminino, produtivo e reprodutivo, retirando-o da esfera das relações privadas, desnaturalizando-o enquanto instinto feminino, ou enquanto expressão do 'amor materno', e ressignificando-o enquanto trabalho (explorado e não pago), configurando o que se denominou como "dupla jornada de trabalho"11.

Kergoat $^{18}$ postula que relações sociais de sexo e divisão social do trabalho são duas proposições indissociáveis que formam um único sistema. A autora considera que esses dois conceitos são inseparáveis pois é a análise em termos de divi- são sexual do trabalho que permite demonstrar a existência de uma relação social específica entre os grupos de sexo, evidenciando que (...) as separações entre homens e mulheres não são redutiveis a mais ou menos exploração ou a uma divisão desigual, mas que se trata de um tratamento contraditório segundo o $\operatorname{sexo}^{19}$ (p. 2). Essas desigualdades podem ser facilmente identificadas através da análise de dados objetivos e subjetivos do processo de trabalho. De acordo com esta autora, o feminismo fez emergir as categorias de sexo como categorias sociais, mostrando que os papéis sociais de homens e mulheres são construções sociais que estão ancoradas e sobredeterminadas por uma base material, e não apenas sócio-ideológica. Desta forma, o conceito de divisão sexual do trabalho fornece a base material - histórica, social e econômica - que permite a crítica sobre os modos de conceituação das ciências, que naturalizam as características sexuadas do trabalho feminino, reduzindo-o à esfera da determinação biológica. Portanto, o trabalho, em suas inseparáveis dimensões produtiva e reprodutiva, está no centro das relações de gênero, e é através desta perspectiva que iremos compreender criticamente o trabalho e a saúde das docentes universitárias.

\section{Metodologia}

Trata-se de uma pesquisa social de caráter qualitativo que adotou a vertente da teoria de Paulo Freire $^{20}$ e dos estudos participativos, com destaque para a sua natureza dialógica ${ }^{21}$. Neste enfoque, postula-se que é por meio do diálogo que se tem acesso aos dados de investigação, sendo possível, a partir do seu conteúdo, a identificação de temas na qualidade de unidades geradoras do conhecimento, ou seja, chaves de análise para problematização e interpretação da realidade. Nesta linha de compreensão, os grupos de discussão são fontes de conhecimento e fornecem dados a serem objetos de reflexão e interpretação crítica, conferindo uma conotação epistemológica ao diálogo ${ }^{20}$. Ganha destaque, aqui, a fala do(a) trabalhador(a) oprimido(a) como sujeito do processo de conhecimento, construindo-se a crítica coletiva de modo colegiado e por meio da educação recíproca, com potencial de desdobramentos para a ação. Na prática, criam-se as condições necessárias para que o grupo opere a transformação da realidade por meio da análise crítica e reflexão a respeito do trabalho e suas relações, atravessado pela divisão sexual do trabalho. 
No tocante aos procedimentos de pesquisa, lançou-se mão de duas técnicas de investigação de natureza qualitativa e participativa: "oficinas em saúde do trabalhador" 22 e "cadernetas de saúde e trabalho" ${ }^{23}$. As oficinas em saúde do trabalhador se constituem como espaços onde trabalhadores(as) e pesquisadores(as) discutem temas de trabalho relacionados à saúde, baseados em elementos da investigação participativa e da pedagogia freireana, e ainda dos fundamentos do campo da saúde do trabalhador. Quanto às cadernetas de saúde e trabalho, consistem em um instrumento de investigação inspirado na experiência sindical italiana ${ }^{24}$. Concebidas como caderno de pequeno porte com a funcionalidade de diário de campo, permite que trabalhadores(as) registrem suas experiências de trabalho e da vida cotidiana, colocando o trabalho como centro das observações e registros em relação à saúde.

No campo de estudo, foram realizadas quatro oficinas e a aplicação de oito cadernetas. As oficinas ocorreram entre os anos de 2015 e 2016, com duração de duas horas aproximadamente, nas dependências de um Instituto pertencente a uma Instituição Federal de Ensino Superior (IFES). Já as cadernetas foram apresentadas e distribuídas entre os(as) participantes durante a reunião das oficinas, bem como a explicação sobre seu preenchimento.

No tocante ao perfil dos sujeitos do estudo, participaram das oficinas dez docentes, sendo seis do sexo feminino e quatro do masculino. Quanto às cadernetas, participaram oito docentes, cinco do sexo feminino e três do masculino, na faixa de idade entre trinta e cinquenta anos. Todo(a)s tinham titulação de doutorado, vínculo de trabalho estável em regime de dedicação exclusiva e atuação na graduação e na pós-graduação. O critério de inclusão foi ser docente ativo(a) e pertencer ao mesmo instituto da IFES. O critério de exclusão foi ser docente em situação de afastamento por motivo de licença ou férias.

A análise do material foi efetuada por meio da técnica de análise de conteúdo, na modalidade temática. Assim, a partir dos materiais transcritos das gravações dos diálogos das oficinas e dos registros escritos nas cadernetas, foram identificados quatro temas principais de análise, a saber: conflitos entre trabalho docente e trabalho doméstico; trabalho docente, maternidade e culpa; políticas de avaliação do trabalho docente e relações de gênero; e divisão sexual do trabalho e docência. Observe-se que esses temas foram constituídos por meio de classificação de excertos por critério de similaridade, frequência e rele- vância em relação à temática de gênero, trabalho e saúde.

No que tange à apresentação dos resultados, convencionou-se a utilização de um recurso alfanumérico, isto é, usou-se uma letra acompanhada de uma numeração, sendo que empregou-se "O" para aludirmos às falas procedentes das Oficinas, e "C" ao nos referirmos aos registros advindos das cadernetas. Quanto à numeração, referese à identificação aleatória dos professores(as) participantes.

Este estudo obteve aprovação do Comitê de Ética em Pesquisa da Escola Nacional de Saúde Pública Sergio Arouca (ENSP/Fiocruz), em 2013.

\section{Resultados e Discussão}

\section{Conflitos entre trabalho docente e trabalho doméstico}

Os resultados obtidos no decurso dos diálogos das oficinas e registro das cadernetas sinalizaram o quanto as demandas da esfera produtiva têm extrapolado o tempo da jornada de trabalho para a esfera reprodutiva e a vida privada, sobretudo das professoras. As 24 horas do dia são insuficientes para compatibilizar trabalho na universidade, trabalho doméstico, cuidado dos filhos e demais atividades da vida privada. O estudo de Rodrigues et al. ${ }^{25}$ evidenciou que a organização do tempo de trabalho dos(as) professores(as) universitários(as) demonstra outras faces do conceito de "sociedade 24 horas", considerando a exigência de trabalho em horários não diurnos e em fins de semana. Segundo as autoras, docentes vivenciam um quadro de excesso de demandas no trabalho. Trata-se de um conjunto de solicitações que, sob a ótica dos(as) docentes, precisam ser cumpridas, ainda que ultrapassem o horário formal de trabalho. Essa situação dramática tem sido vivenciada em desvantagem pelas docentes mulheres, o que compromete a luta e a defesa pela saúde, acarretando conflitos que podem levar a processos de adoecimento físico e psíquico.

As 20:30h, depois de todos os afazeres domésticos feitos, reinicio meu trabalho. Toda hora minha filha de 9 anos vem ver se eu já terminei. Sinto remorso por não estar com ela. Digo que hoje preciso trabalhar mais. Às 10:30h resolvo ir sentar com ela na frente da TV, mas com o computador junto [...] Às 11:40 h (23:40h) desisto. Vou dormir. (C6).

Observou-se certa naturalização sobre a necessidade de que uma parte do trabalho docente seja realizado em casa. Essa intensificação do 
trabalho denota precarização das relações ${ }^{26}$ que a categoria docente vem sofrendo nas últimas décadas. Para mães com filhos pequenos, ter que lidar com essa sobrecarga é ainda mais difícil. O árduo exercício do papel materno exige uma forte mobilização subjetiva, afetiva e até mesmo física, que torna desafiador conciliar com a "disponibilidade" para a extensão do trabalho em casa, visto que o trabalho docente exige considerável capacidade de concentração, abstração, análise e reflexão. As professoras sinalizaram que não se trata de uma escolha: elas insistem em tentar superar o conflito, em realizar essa conciliação. São conscientes de que a dedicação extra ao trabalho tem se mostrado essencial para alcançar os rígidos critérios de avaliação.

Com filho pequeno, eu não consigo mesmo. Há muito tempo que não consigo trabalhar [em casa], é muito raro, só quando tem alguma coisa assim, muito específica, que eu falo para o meu marido: segura aí, vai embora com elas porque eu não tenho como. Mas é muito raro. (O3).

$\mathrm{Eu}$, por exemplo, acho que com os filhos, vai somando as coisas, vai chegar, vai dar jantar, vai trabalhar depois de certa hora, eu acho que, se duvidar, não tem ninguém que durma a quantidade de horas que devia dormir. Eu tenho a sensação. Eu vivo cansada. Não é nem com sono, é cansada e a memória ruim. (O5).

A situação pode se agravar quando coexistem outros vínculos de trabalho, o que não é incomum entre docentes universitários que ingressaram mais recentemente na universidade, com salários menores e maiores exigências para a progressão na carreira. Seguramente, a sobrecarga de trabalho pode afetar a saúde das professoras, inclusive no que diz respeito a problemas relacionados a distúrbios do sono. Constatação semelhante é mencionada por Rotenberg e $\operatorname{Carlos}^{27}$, ao assegurarem que professores(as) universitários(as) possuem ritmos de trabalho acelerado. Segundo as autoras, os(as) docentes sentem-se em constante dívida profissional, levando-os(as) a trabalhar após a jornada formal. Este comportamento faz com que o(a) trabalhador(a) tenha um ciclo vigília-sono irregular, o que é acompanhado de privação parcial do sono, acarretando consequências negativas para a saúde e para o próprio desempenho no trabalho.

Nesse momento eu comecei a ter que dar conta de várias coisas, dando aula, eu era professora, trabalhava em uma universidade particular, era professora também do estado, da escola técnica e enfim, o tempo que eu tinha, e ainda tinha um fitho pequeno, e o tempo que eu tinha era de madru- gada, para dar conta de tudo que eu tinha que dar conta. (O3).

A gente leva tese para casa. A gente é cobrada para escrever artigos. E o marido! Ele fala... Mas eu não posso porque tenho que terminar o artigo. E o marido fala: Você trabalha o tempo inteiro! (O2).

Foi possível entrever, em algumas falas, a ausência da participação dos parceiros na divisão do trabalho doméstico, o que sugere que, mesmo em uma carreira intelectual, de nível universitário e que desfruta de prestígio social, a divisão sexual do trabalho permanece, implicando em alto custo para as mulheres e, por consequência, para seus filhos. O que reitera o quanto as raízes da divisão sexual do trabalho encontram-se profundas na família e na sociedade ${ }^{28}$. Se, por um lado, o acesso ao trabalho remunerado poderia se constituir na base da autonomia das mulheres, vê-se, por outro, que as relações sociais de sexo continuam perpassadas pela exploração e apropriação ${ }^{29}$.

\section{Trabalho docente, maternidade e culpa}

As relações sociais de sexo que atravessam as sociedades capitalistas contemporâneas estabelecem expectativas para as mulheres que permanecem em todas as etapas da vida, desde o seu nascimento. Mesmo com relativas conquistas de autonomia e auto-realização, a ideia de que a maternidade é central na vida das mulheres permanece inalterada, assim como a divisão sexual do trabalho. Dessa forma, as mulheres, ao entrarem no mercado de trabalho com justos anseios de auto-realização, continuam se sentindo responsáveis pelo cuidado da casa e dos filhos. O desafio de 'conciliação' dessas duas esferas que são, por definição, conflitivas ${ }^{11}$, faz com que se desdobrem e se desgastem, física e psiquicamente, ao perceberem que não conseguem alcançar a contento todos esses objetivos. Como conseqüência desta construção histórica dos papéis, é frequente muitas mulheres se cobrarem, e se culparem, pelo pouco tempo dedicado aos filhos, especialmente quando pequenos.

A gente volta da licença maternidade, você está com a cabeça lá, na filha que ainda é pequenininha ... Aí eu venho para cá, tenho um milhão de coisas para fazer, eu vou embora com um milhão mais um [...] Eu sempre falo, estou sempre devendo. Estou devendo aqui, em casa. (O2).

Hoje estou particularmente triste pois minha filha participará da cerimônia da bandeira na escola e não conseguirei estar presente. Sei que este é o ônus, ou um deles, do trabalho, mas não consigo não me sentir culpada. (C6). 
Os depoimentos das professoras que participaram desta pesquisa permitiram evidenciar o quanto são conflitivas as esferas do trabalho e da vida familiar para as mulheres que, muitas vezes, arcam sozinhas com cobranças e auto-cobranças em uma sociedade em que o que (ainda) se espera das mulheres, acima de tudo, é que sejam boas mães.

\section{Políticas de avaliação do trabalho docente e relações de gênero}

Durante os diálogos com professores(as) foi possível perceber diferentes nuances das relações de gênero no âmbito do trabalho do ensino superior, sendo que um dos temas que ganhou destaque foi o das políticas de avaliação do trabalho docente. Na visão das professoras, um dos principais fatores de impedimento do reconhecimento e ascensão profissional de mulheres em universidades diz respeito aos diversos processos de avaliação atualmente em vigor, que prescrevem normas discriminatórias que suscitam, na prática, desigualdades de gênero.

Aí, receberam de volta as avaliações. Das mulheres, o mesmo projeto, a conta era diferente, era menor. Então, a avaliação era pior se tivesse o nome de uma mulher. Então, isso eu acho que tem. Que é o viés da avaliação. (O7).

Tem uma série de impactos, eu sempre falei isso, um viés mesmo de avaliação: quando é uma mulher, quando é um homem, é diferente. (O6).

As docentes referiram-se às implicações da questão de gênero nos processos de avaliação em universidades públicas com o uso da expressão "viés". A interpretação de "viés" pode ser significada como processos institucionais que discriminam e oprimem mulheres. Na visão das professoras, as diferentes formas de avaliação em universidades aprofundam as desigualdades de gênero e mostram o preconceito arraigado contra mulheres no âmbito das relações institucionais de trabalho. Neste ponto, cabe ressaltar que, para Kergoat ${ }^{18}$, o conceito de relações sociais de sexo deve estar sempre interconectado à noção de prática social, o que permite re-estabelecer as indissolúveis relações entre o material e o simbólico. E isso constitui um grande desafio, haja visto que as relações de trabalho e de poder entre os sexos mostram que a hierarquia do masculino e do feminino ainda continua ativa ${ }^{30}$.

No que diz respeito as atuais políticas de avaliação do ensino superior no Brasil, é fundamental a referência à Lei n. 10.861 de 14 de abril de 2004, que criou o Sistema Nacional de Avaliação da Educação Superior (SINAES) ${ }^{31}$. A instituição dessa política expressa o conceito de Estado avaliador e o modelo de gestão pública orientada para resultados, balizada em princípios políticos e sociais de natureza neoliberal. Ribeiro ${ }^{32}$ assevera que a ênfase do SINAES recai sobre o controle dos trabalhadores por meio de avaliações finalísticas, o que provoca competitividade e antagonismos. Consoante a autora, deve-se desenvolver uma concepção formativa e pedagógica de avaliação, oportunizando novos olhares para a universidade em todas as suas dimensões, com vistas à consolidação de uma cultura avaliativa que, a nosso ver, deve necessariamente incorporar a perspectiva das relações sociais de sexo e de gênero ${ }^{18,33}$.

O que eu acho que tem, talvez, não sei se é um preconceito, se você vai olhar justamente os cargos de gestão, reitora, pesquisador do CNPQ, quantas mulheres tem, quantos homens tem? (O6).

Constatou-se, durante os diálogos, que poder e prestígio no âmbito das universidades possuem uma profunda conotação de gênero. Massarani et al. ${ }^{34}$ chamam atenção para a questão da invisibilidade das mulheres nas ciências e afirmam a falácia de que a ciência brasileira se constitua como espaço somente de homens. E, de fato, dados disponíveis no Diretório dos grupos de pesquisa no Brasil $^{35}$, acessíveis na Plataforma Lattes, mostram que, no ano de 2016, a distribuição percentual dos(as) pesquisadores(as) segundo o sexo é exatamente a mesma: $50 \%$ homens e $50 \%$ mulheres. No entanto, sabe-se que existem desequilíbrios na ocupação de áreas de maior prestígio, como nas ciências exatas, e na ocupação de cargos hierárquicos superiores. Löwy ${ }^{36}$ assegura a subsistência da estreita relação histórica entre ciências e gênero, moldada pela dicotomia elementar entre masculino e feminino na sociedade, uma rígida bipartição que deve ser analisada e criticamente apoiada na constatação da dominação social e cultural das ciências pelos homens, pertencentes ao ocidente e membros das classes dominantes.

Isto posto, cabe destacar a importância de se conceber o trabalho em universidades no contexto do tempo e do lugar de sua produção. Portanto, na visão das professoras, um tópico importante no trabalho da ciência contemporânea constitui-se na construção e revisão de instrumentos e ferramentas que servem como referência ao processo de avaliação do trabalho docente, tal qual o reexame da Plataforma Lattes possibilitaria.

Recentemente veio uma menina de Londres e ela falou que agora na Inglaterra as mulheres botam no currículo que teve filho. Ano tal, nasceu fulano de tal. E aí as pessoas quando avaliarem o 
seu currículo sabem que naquele ano você teve filho [...] É obvio que tem impacto. Essa frustração de você não dar conta do que você tem que fazer. (O2).

$\mathrm{Na}$ ótica das docentes, os critérios de avaliação do trabalho de professores(as) que são prescritos pelos órgãos governamentais responsáveis pela política de pós-graduação no Brasil, como CNPq e CAPES, acabam sendo mais rígidos para as professoras mulheres do que para os professores homens, gerando uma situação de desigualdade e discriminação. Destarte, o tema das políticas públicas relacionadas à maternidade $\mathrm{e}$ ao trabalho de professoras deve ser retomado de maneira a se tornar realidade. Portanto, medidas anunciadas pelo $\mathrm{CNPq}$, no início do ano de 2019, como a inclusão da data de nascimento ou adoção de filhos no Currículo Lattes, que teriam caráter protetivo à mulher e à maternidade, ainda não tem data para serem implantadas e deveria resultar, efetivamente, em mudanças nos critérios de avaliação do trabalho docente.

No plano internacional, estudos como os de Kapareliotis e Miliopoulou ${ }^{37}$ observaram que, mesmo na União Européia (UE), que tem enfatizado a necessidade de igualdade de gênero através da criação de políticas e instruções, ainda existem consideráveis diferenças entre os estados membros da UE em relação à legislação, regulamentação e políticas institucionais. E até mesmo em países que lutam ativamente pela igualdade entre os gêneros, como a Suécia, Gunn et al. ${ }^{38}$ encontraram evidências que algumas mulheres desconhecem as políticas feitas para apoiá-las, ou mesmo relutam em usá-las. Por outro lado, há países com políticas de igualdade ou de antidiscriminação que são limitadas ou inexistentes.

Observou-se, pelos relatos das professoras, mal-estar e sofrimento, que foram enunciados por meio de expressões e sintomas relacionados à saúde mental, tais como angústia, tristeza e depressão. Trata-se de manifestações de insatisfação e frustração alusivas ao desejo de se obter reconhecimento na carreira acadêmica nos padrões estabelecidos pelos órgãos de avaliação.

Meu currículo não é forte suficiente para garantir o retorno do meu trabalho em casa. Vontade de chorar. (C5).

Final de semana elas [filhas] exigem, elas querem e eu amo estar com elas, eu curto mesmo. E ai a produção cai, obvio. E aí a angústia aumenta. (O3).

Em face das ponderações, notou-se conflitos de ordem emocional no que diz respeito a conciliação entre ser mãe, ser docente e pesquisadora. Concorda-se com Hirata ${ }^{33}$ quando afirma que a divisão sexual do trabalho, sob qualquer circunstância, não pode ser explicada ou elucidada sem que se recorra à dimensão extratrabalho, ou seja, a relação entre trabalho e universo doméstico. E, de fato, as professoras, para alcançarem metas de produção e manter status na comunidade acadêmica, precisam trabalhar mais, o que implica levar trabalho pra casa, entrelaçando atividade de trabalho com cuidados da vida familiar, o que certamente resulta em custos para a saúde.

Tem o parto, amamenta e até, durante certo tempo, não tem outro jeito, na amamentação essa ligação é muito forte [...] Além da cultura, tem o lado mesmo fisiológico dessa relação que faz com que a gente tenha pouco tempo e pouca cabeça para trabalhar, menos cabeça para trabalhar. (O6).

Uma vez eu andando na praia aí eu encontro a coordenadora da pós, daqui, lendo uma tese, caminhando. Eu parei e falei - (X) você vai cair. Anda, depois você lê. "Ué, eu sei fazer várias coisas ao mesmo tempo. Você não faz?” (O3).

$\mathrm{O}$ aspecto mais preocupante aí inscrito consiste na subordinação do tempo social das professoras ao tempo de trabalho e à esfera econômica, típico do modo de produção capitalista. Neste sentido, o debate público sobre o tempo laboral é fundamental para diminuir a diferenciação entre homens e mulheres e, consequentemente, as desigualdades de gênero ${ }^{39}$. Daí defende-se a importância em se elaborar políticas públicas específicas voltadas à valorização do trabalho feminino em universidades.

É digna de nota, ainda, a menção, por parte das professoras, durante o processo de pesquisa, ao "Programa Mulheres na Ciência", criado em 2005 para promover relações de gênero mais equânimes no campo da Ciência e Tecnologia, com destaque para a prorrogação de bolsas em caso de parto ou adoção. Portanto, no tocante às Políticas de avaliação do trabalho docente e as relações de gênero, torna-se indispensável realizar debates de modo a torná-las democráticas e participativas, o que pressupõe o engajamento majoritário das próprias docentes mulheres.

\section{Divisão sexual do trabalho e docência}

Kergoat $^{5}$ assevera que a divisão sexual do trabalho revela dois princípios gerais nas relações sociais de sexo: o princípio da separação caracterizado pela diferença entre o trabalho do homem e o trabalho da mulher, e o princípio da hierarquia, onde o trabalho do homem vale mais do que o trabalho da mulher. Para Federi$\mathrm{Ci}^{40}$, a desigualdade do trabalho entre homens e 
mulheres se traduz pela valorização e produção da riqueza, tidas como consequentes, majoritariamente, do trabalho produtivo destinado aos homens. Diferentemente do trabalho reprodutivo destinado às mulheres que, embora fundamental, é apropriado pelo trabalho produtivo e naturalizado como trabalho gratuito e desvalorizado. Tais desigualdades também podem ser observadas nas vidas das docentes universitárias participantes do estudo.

Minha mãe fala isso para mim: você não pode reclamar do $V$ [marido] porque ele te ajuda muito. Antigamente eles realmente não faziam nada. (O6).

Acordo as 4:30, opto por reler a dissertação de mestrado pois serei da banca hoje às $14 \mathrm{~h}$ na UERJ. [...] Às 7 horas, acordo minha filha e marido. Peço para ele levá-la ao violão, mas ele se atrasa. Largo tudo e saio correndo. Volto as 09:30h e continuo na dissertação. Trabalhar em casa é ruim, muitos distratores. Tento me concentrar. (C6).

Deste modo, a avaliação do trabalho docente de mulheres deve incorporar o trabalho não acadêmico: [...] que precisou fazer antes de chegar ao trabalho? Quem fez seu jantar, arrumou sua cama e aliviou seu estresse para que ela pudesse voltar ao trabalho após uma jornada fatigante, dia após dia? [...] Não apenas para si, mas também para os demais membros da família? ${ }^{41}$ (p. 108).

Por outro lado, e reforçando mais uma vez que os significados positivos ou negativos com relação à profissão docente atribuídos às mulheres ou aos homens não podem ser fixos, imutáveis e colados ao sexo de quem exerce a docência, deve-se destacar o papel exercido por alguns homens (mesmo que contra-hegemônicos). Alvarenga e Vianna ${ }^{42}$, por exemplo, em pesquisa com docentes no estado de São Paulo, destacam relato de docente masculino, com filho pequeno, que, mesmo tendo seu tempo ocupado com as atividades docentes, dedica-se ao cuidado do filho, com a intenção de diminuir as inúmeras atividades de responsabilidade da esposa. Nessa mesma direção, o relato de professor participante da pesquisa parece convergir para a ideia da maior participação masculina no trabalho reprodutivo:

Me sinto cansado. Tenho um filho com 01 mês e meio e a licença paternidade é muito curta. Tenho ficado acordado boa parte da noite. Por sorte, estamos já na parte do período letivo com poucas aulas. (C2).

Hirata e Kergoat ${ }^{11}$, ao identificarem novas configurações da divisão sexual do trabalho, destacaram que, mesmo longe do equilíbrio, iniciou-se maior envolvimento masculino no trabalho doméstico. Porém, no contexto da reconfiguração das relações sociais de sexo, ainda são reproduzidas desigualdades de gênero nas relações do trabalho docente. É preciso investimentos por meio de políticas públicas, educacionais e sociais que garantam igualdade de oportunidades e melhores condições de vida para as docentes, sendo igualmente fundamental que estudos nesta temática sejam debatidos, visibilizados e aprofundados.

\section{Considerações finais}

O diálogo entre pesquisadores(as) e professores(as) estimulou o debate acerca de estratégias para superar as consequências da rígida divisão sexual do trabalho em universidades por meio da crítica a respeito do capitalismo gerencialista (im)posto nas IFES. Por certo, o tema da divisão sexual do trabalho em universidades públicas desponta como importante questão que evidencia sobrecarga de trabalho e sofrimento, assegurando que a análise da vida laboral das mulheres não pode ser dissociada da esfera privada, especialmente em um momento em que o trabalho docente se torna crescentemente competitivo e baseado em critérios de avaliação cada vez mais rígidos. Afinal, como o feminismo vem evidenciando através dos tempos, "a classe trabalhadora tem dois sexos" ${ }^{28}$ e, nos espaços de trabalho remunerado, as trabalhadoras ainda estão em situação de desvantagem e desigualdade. 


\section{Colaboradores}

KR Souza e RH Simões-Barbosa participaram da concepção, delineamento do manuscrito, análise e interpretação dos dados e da redação do artigo. Quanto às autoras AMS Rodrigues, EG Felix, L Gomes e MBM Santos participaram da interpretação dos dados, redação do artigo e aprovação da versão a ser publicada.

\section{Referências}

1. Vieira RB. O programa para a educação superior de Jair Bolsonaro: empreendedorismo, controle e ofensiva sobre o fundo público. Univ Soc 2019; (64):90-101.

2. Lacaz FAC. Capitalismo organizacional e trabalho: a saúde do docente. Univ Soc 2010; (45):51-59.

3. Leher R. Ideias, valores e princípios para afirmar o futuro da universidade pública latinoamericana. RIICE 2018; (44):133-146.

4. Souza KR, Mendonça ALO, Rodrigues AMS, Felix EG, Teixeira LR, Santos MBM, Moura M. A nova organização do trabalho na universidade pública: consequências coletivas da precarização na saúde dos docentes. Cien Saude Colet 2017; 22(11):3667-3676.

5. Kergoat D. Dinâmica e consubstancialidade das relações sociais. Novos Estudos - Cebrap 2010; (86):93103.

6. Schneider EC. Mulheres em greve e algumas condições para a construção da Política Institucional de Equidade de Gênero na UNILA. Univ Soc 2019; (64):20-29.

7. Siqueira SMM. É preciso estar atenta e forte: apontamentos para uma análise dos impactos da reforma trabalhista na vida das trabalhadoras. Univ Soc 2019; (64):8-19.

8. Araujo TM, Godinho TM, Reis EJFB, Almeida MMG. Diferenciais de gênero no trabalho docente e repercussões sobre a saúde. Cien Saude Colet 2006; 11(4):1117-1129.

9. Velho L, León E. A construção social da Produção científica por Mulheres. Cadernos Pagu 1998; (10):309-344.

10. Hoffmann C, Zanini RR, Moura GL, Costa VMF, Comoretto E. Psicodinâmica do trabalho e riscos de adoecimento no magistério superior. Estudos Avançados 2017; 31(91):257-276.

11. Hirata H, Kergoat D. Novas configurações da divisão sexual do trabalho. Cad Pesquisa 2007; 37(132):595609.

12. Hirata H. Gênero, Patriarcado, Trabalho e Classe. Trabalho Necessário 2018; 16(29):14-27.

13. Saffioti HIB. Rearticulando gênero e classe social. In: Costa AO, Bruschini C., organizadores. Uma questão de gênero. Rio de Janeiro: Rosa dos Tempos; 1992.

14. Lauretis T. A tecnologia do gênero. In: Hollanda HB, organizadores. Tendências e impasses: o feminismo como crítica da cultura. Rio de Janeiro: Rocco; 1994.

15. Simões-Barbosa RH. Mulheres, reprodução e Aids: as tramas da ideologia na assistência à saúde de gestantes HIV+. 2001 [tese]. Rio de Janeiro: Escola Nacional de Saúde Pública Sergio Arouca, Fundação Oswaldo Cruz; 2001.

16. Davis A. Mulheres, raça e classe. São Paulo: Boitempo; 2016.

17. Arruzza C, Bhattacharya T, Fraser N. Feminismo para os 99\%. São Paulo: Boitempo; 2019.

18. Kergoat D. Divisão sexual do trabalho e relações sociais de sexo. In: Hirata H, Laborie F, Le Doaré H, Senotier D, organizadores. Dicionário crítico do feminismo. São Paulo: Ed. Unesp; 2009.

19. Kergoat D. Relações sociais de sexo e divisão sexual do trabalho. In: Lopes MJM, Meyer DE, Waldow VR, organizadores. Gênero e saúde. Porto Alegre: Artes Médicas;1996. 
20. Freire P. Pedagogia do Oprimido. Rio de Janeiro: Paz e Terra; 2014.

21. Brandão CR, Streck DR. Pesquisa participante: a partilha do saber. São Paulo: Ideias \& Letras; 2006.

22. Souza KR, Rodrigues AMS, Santos MBM, Simões -Barbosa RH, Fernandez VS, Mendonça ALO. Oficinas em saúde do trabalhador: ação educativa e produção dialógica de conhecimento acerca das relações entre trabalho docente e saúde em universidade pública. Rev Bras Saude Ocup 2020; 45(e4):1-9.

23. Souza KR, Fernandez VS, Teixeira LR, Larentis AL, Mendonça ALO, Felix EG, Santos MBM, Rodrigues MAS, Moura M, Simões-Barbosa RH, Barros WO, Almeida MG. Cadernetas de saúde e trabalho: diários de professores de universidade pública. Cad Saude Publica 2018; (34):01-11.

24. Oddone I, Marri G, Gloria S. Ambiente de trabalho: a luta dos trabalhadores pela saúde. São Paulo: Hucitec; 1986.

25. Rodrigues AMS, Souza KR, Teixeira LR, Larentis AL. A temporalidade social do trabalho docente em universidade pública e a saúde. Cien Saude Colet 2020; (25):1829-1838.

26. Hirata $H$. Tendências recentes da precarização social e do trabalho: Brasil, França, Japão. Cad. CRH 2011; 24 (01):15-22.

27. Rotenberg L, Carlos RSL. How social acceleration affects the work practices of academics: A study in Brazil. German Journal of Human. Resource Management 2018; 32(3-4):257-270.

28. Souza-Lobo E. A classe operária tem dois sexos: trabalho, dominação e resistência. São Paulo: Editora Perseu Abramo; 2011.

29. Kergoat D. O trabalho, um conceito central para os estudos de gênero? In: Maruani $M$, organizadora. Trabalho, logo existo: perspectivas feministas. Rio de Janeiro: FGV Editora; 2019.

30. Blass L, Hirata H, Soares V. Prefácio à 2a edição. In: Souza-Lobo, Elisabeth. A classe operária tem dois sexos: trabalho, dominação e resistência. São Paulo: Editora Perseu Abramo; 2011.

31. Brasil. Lei no 10.861 , de 14 de Abril de 2004. Institui o Sistema Nacional de Avaliação da Educação Superior SINAES. Brasília: Presidência da República; 2004.

32. Ribeiro EA. As atuais políticas públicas de avaliação para a educação superior e os impactos na configuração do trabalho docente. Avaliação (Campinas) 2012; 17(2):299-316.

33. Hirata H. A precarização e a divisão internacional e sexual do trabalho. Sociologias 2009; 21:24-41.

34. Massarani L, Castelfranchi Y, Pedreira AE. Cientistas na TV: como homens e mulheres da ciência são representados no Jornal Nacional e no Fantástico. Cad Pagu 2019; 56 (e195615):1-34.
35. Conselho Nacional de Desenvolvimento Científico e Tecnológico (CNPq). Diretório dos Grupos de Pesquisa. Séries Históricas Pesquisadores por sexo [Internet]. Brasília: CNPq; 2020 [acessado 2020 abr 20]. Disponível em: http://lattes.cnpq.br/web/dgp/pesquisadores-por-sexo.

36. Löwy, I. Ciências e gênero. In: Hirata H, Laborie F, Doaré $\mathrm{H}$, Senotier D, organizadores. Dicionário crítico do feminismo. São Paulo: ed. UNESP; 2009.

37. Kapareliotis I, Miliopoulou GZ. "Gender Bias in Academia: An Attempt to Render the Intangible Tangible". In: Diversity within Diversity Management (Advanced Series in Management. Emerald Publishing Limited 2019; (22):247-271.

38. Gunn CM, Freund KM, Kaplan SA, Raj A, Carr PL. Knowledge and perceptions of family leave policies among female faculty inacademic medicine. Women's Health Issues 2014; 24(2):205-210.

39. Dedecca CS. Tempo, Trabalho e Gênero. In: Costa AA, Oliveira EM, Lima MEB, Soares V, organizadores. Reconfiguração das relações de gênero no trabalho. São Paulo: CUT Brasil; 2004.

40. Federici S. Calibã e a bruxa: mulheres, corpo e acumulação primitiva. São Paulo: Elefante; 2017.

41. Arruzza C, Bhattacharya T, Fraser N. Feminismo para os 99\%: um manifesto. São Paulo: Boitempo; 2019.

42. Alvarenga CF, Vianna C. Relações sociais de gênero e divisão sexual do trabalho: desafios para a compreensão do uso do tempo no trabalho docente. Laboreal 2012; 8(1):11-27.

Artigo apresentado em 08/06/2020

Aprovado em 04/07/2021

Versão final apresentada em 06/07/2021

Editores-chefes: Romeu Gomes, Antônio Augusto Moura da Silva 